\title{
Somatosensory Projections to Cochlear Nucleus Are Upregulated after Unilateral Deafness
}

\author{
Chunhua Zeng, ${ }^{1}$ Ziheng Yang, ${ }^{1}$ Lauren Shreve, ${ }^{1}$ Sanford Bledsoe, ${ }^{1}$ and Susan Shore ${ }^{1,2}$ \\ ${ }^{1}$ Kresge Hearing Research Institute, Department of Otolaryngology, and ${ }^{2}$ Department of Molecular and Integrative Physiology, University of Michigan, Ann \\ Arbor, Michigan 48109-0506
}

The cochlear nucleus $(\mathrm{CN})$ receives innervation from auditory and somatosensory structures, which can be identified using vesicular glutamate transporters, VGLUT1 and VGLUT2. VGLUT1 is highly expressed in the magnocellular ventral CN (VCN), which receives auditory nerve inputs. VGLUT2 is predominantly expressed in the granule cell domain (GCD), which receives nonauditory inputs from somatosensory nuclei, including spinal trigeminal nucleus $(\mathrm{Sp} 5)$ and cuneate nucleus $(\mathrm{Cu})$. Two weeks after unilateral deafening VGLUT1 is significantly decreased in ipsilateral VCN while VGLUT2 is significantly increased in the ipsilateral GCD (Zeng et al., 2009), putatively reflecting decreased inputs from auditory nerve and increased inputs from nonauditory structures in guinea pigs. Here, we wished to determine whether the upregulation of VGLUT2 represents increases in the number of somatosensory projections to the CN that are maintained for longer periods of time. Thus, we examined concurrent changes in VGLUT levels and somatosensory projections in the $\mathrm{CN}$ using immunohistochemistry combined with anterograde tract tracing three and six weeks following unilateral deafening. The data reveal that unilateral deafness leads to increased numbers of VGLUT2-colabeled Sp5 and Cu projections to the ventral and dorsal CN. These findings suggest that $\mathrm{Sp} 5$ and Cu play significant and unique roles in cross-modal compensation and that, unlike after shorter term deafness, neurons in the magnocellular regions also participate in the compensation. The enhanced glutamatergic somatosensory projections to the $\mathrm{CN}$ may play a role in neural spontaneous hyperactivity associated with tinnitus.

\section{Introduction}

The cochlear nucleus $(\mathrm{CN})$ receives auditory inputs from type I auditory nerve fibers (ANFs) and nonauditory inputs from several somatosensory nuclei, including the spinal trigeminal nucleus (Sp5), trigeminal ganglion, cuneate nucleus $(\mathrm{Cu})$, vestibular nuclei, and contralateral CN (Burian and Gstoettner, 1988; Bukowska, 2002; Zhou and Shore, 2004; Haenggeli et al., 2005; Doucet et al., 2009; Zhou et al., 2010; Zeng et al., 2011; Barker et al., 2012). The nonauditory projections terminate predominantly in the $\mathrm{CN}$ granule cell domain (GCD) (Zhan and Ryugo, 2007; Zhou et al., 2007; Zeng et al., 2011), which includes the superficial shell region of ventral $\mathrm{CN}(\mathrm{VCN})$ and the fusiform cell layer of dorsal cochlear nucleus (DCN) (Mugnaini et al., 1980; Hackney et al., 1990; Weedman et al., 1996; Zhou and Shore, 2004). These projections give $\mathrm{CN}$ the unique ability to integrate information from the auditory nerve and somatosensory system (Shore, 2005) and compensate to cochlear damage

\footnotetext{
Received May 25, 2012; revised Aug. 15, 2012; accepted Sept. 10, 2012.

Author contributions: S.B. and S.E.S. designed research; C.Z. and L.S. performed research; C.Z., Z.Y., L.S., and S.E.S. analyzed data; C.Z., S.B., and S.E.S. wrote the paper.

This work was supported by Grant R01 DC DC004825 and a core center Grant P30 DC-05188 from the National Institute on Deafness and Other Communication Disorders, National Institutes of Health. We thank Cameron Rule for his critical reading and editing of this manuscript, and Dr. Richard Altschuler and his laboratory for the assessment of spiral ganglion neurons.

Correspondence should be addressed to Susan Shore, Kresge Hearing Research Institute, Department of Otolaryngology, University of Michigan, 1301 East Ann Street, Ann Arbor, Michigan 48109-0506. E-mail: sushore@ umich.edu.

DOI:10.1523/JNEUROSCI.2598-12.2012

Copyright $\odot 2012$ the authors $\quad 0270-6474 / 12 / 3215791-11 \$ 15.00 / 0$
}

(Kaltenbach, 2007; Shore et al., 2008; Zeng et al., 2009; Barker et al., 2012; Dehmel et al., 2012).

The vesicular glutamate transporter subtypes have different distributions in the brain. VGLUT2 is strongly expressed by neurons in auditory subcortical nuclei, whereas VGLUT1 is dominant in the auditory cortex and at variable levels among auditory subcortical nuclei (Hackett and de la Mothe, 2009; Hackett et al., 2011). In the CN, VGLUT1 and VGLUT2 have distinct distributions associated with projections from auditory and somatosensory inputs, respectively (Zhou et al., 2007). VGLUT1 is highly expressed in the magnocellular area of VCN and deep layer of the dorsal cochlear nucleus (DCN3), where ANFs terminate on principal neurons. In contrast, VGLUT2 is expressed mostly in the GCD of the CN, which receives primarily nonauditory inputs from somatosensory nuclei (Zhou et al., 2007). Somatosensory terminals from $\mathrm{Sp} 5, \mathrm{Cu}$, and vestibular nuclei as well as terminals from the contralateral CN colabel with VGLUT2 but rarely VGLUT1, whereas type I ANF terminals exclusively colabel with VGLUT1 (Zhou et al., 2007, 2010; Zeng et al., 2011; Barker et al., 2012). This pathway-specific feature can be used to quantify changes in auditory and somatosensory inputs after unilateral deafening.

Previously, we demonstrated changes in the relative distributions of VGLUT1 and VGLUT2 in the guinea pig CN after unilateral deafening (Zeng et al., 2009): While VGLUT1 decreased in the ipsilateral VCN two weeks after deafening, VGLUT2 increased in the GCD that receives nonauditory inputs (Zeng et al., 2009). These changes suggested an enhancement in nonauditory glutamatergic inputs. However, the sources of these increased 
A

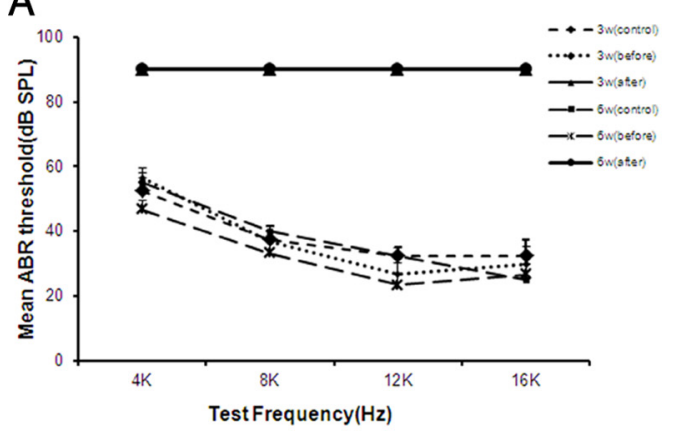

B

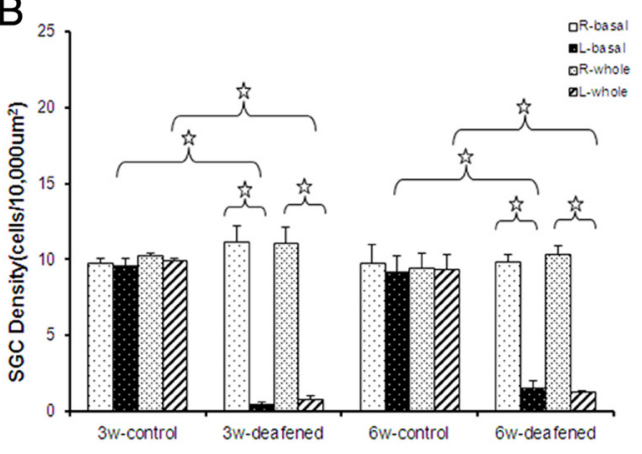

C

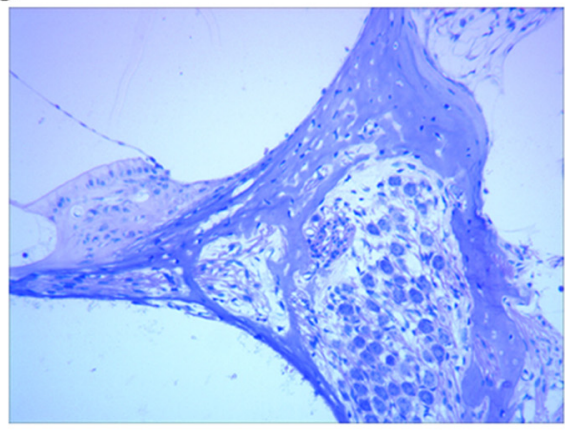

D

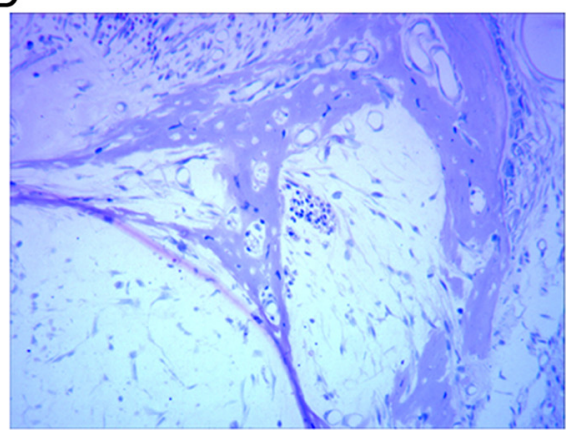

Figure 1. $A$, Mean ABR thresholds for four normal control animals and for six animals three $(N=3)$ and six $(N=3)$ weeks following deafening by an injection of kanamycin into the left cochlea. ABRs on the left (ipsilateral) side are shown before and after deafening compared with the normal controls. ABRs indicate profound deafness in the left ears at both three and six weeks after kanamycin injections. No significant effect of the kanamycin injections was observed in any of the right ears. The black lines at $90 \mathrm{~dB}$ indicate no response at the limit of the speaker. $\boldsymbol{B}$, Spiral ganglion counts for the whole cochlea as well as the basal turn are shown for four normal control animals and for six deafened animals, three $(N=3)$ and six $(N=3)$ weeks after kanamycin injections into the cochlea. The left side for the whole cochlea and the basal turn shows a noticeable loss when compared with the right side and normal controls ( $p<0.01$, open stars). Error bars represent SEM. $C$, Normal appearance of spiral ganglion cells in one control animal. $\boldsymbol{D}$, Significant loss of spiral ganglion cells in one animal after three weeks of deafness.

VGLUT2 levels have not been elucidated. Here, we combined VGLUT immunohistochemistry with anterograde tract tracing to determine whether postdeafening increases in VGLUT2 represented increases in the number of projections from the somatosensory pathways to the $\mathrm{CN}$. The results indicate that following unilateral deafening, an increased number of projections from both Sp5 and $\mathrm{Cu}$ provide the basis for the increased VGLUT2 distributions. Furthermore, these increased projections occurred not only in the GCD, but also in magnocellular regions, suggesting a differential redistribution of somatosensory inputs to the $\mathrm{CN}$.

\section{Materials and Methods}

Eighteen female pigmented guinea pigs (250-350 g, Elm Hill Breeding Labs) with normal Preyer's reflexes were used in this study. Ten were unilaterally deafened and eight were used as controls. To quantify changes in VGLUT isoform levels, three unilaterally deafened animals were allowed to survive for three weeks ( $3 \mathrm{w}$ deafened), and three were allowed to survive for six weeks following the deafening ( $6 \mathrm{w}$ deafened). Two age-matched normal animals were used as control for each group ( $3 \mathrm{w}$ deafened and $6 \mathrm{w}$ deafened). An additional eight animals were used to identify the locations of VGLUT-co-labeled terminals following tracer injections in $\mathrm{Sp} 5$ or $\mathrm{Cu}$. Of these eight animals, four were unilaterally deafened and four were controls. Two deafened animals received tracer injections in $\mathrm{Sp} 5$ and two received injections in $\mathrm{Cu}$ two weeks following deafening. These animals were killed after another week to allow for anterograde tracing. Four age-matched control animals received tracer injections in $\operatorname{Sp} 5(N=2)$ and $\mathrm{Cu}(N=2)$ in the same timeframe as the deafened animals. All animals with tracer injections were allowed to survive for 1 week before being killed. All procedures were performed in accordance with the NIH guidelines for the use and care of laboratory animals (NIH publication No. 80-23), and guidelines provided by the
University Committee on Use and Care of Animals (UCUCA) of the University of Michigan (UCUCA protocol \# 08539).

Auditory brainstem response measurements. Auditory brainstem responses (ABRs) were measured for all animals before and at the end of the experiment before killing. ABRs were recorded in an electrically and acoustically shielded chamber (Acoustic Systems). Animals were anesthetized with ketamine $(40 \mathrm{mg} / \mathrm{kg})$ and xylazine $(10 \mathrm{mg} / \mathrm{kg})$ and body temperature was maintained with a thermostatically controlled heating pad. Subdermal recording electrodes were placed at vertex (one $\mathrm{cm}$ posterior to bregma), reference (ventral to the pinna on the tested ear), and ground (ventral to the pinna on the contralateral ear) sites.

Digital signals were generated and delivered by Tucker Davis Technologies (TDT) hardware controlled by a Pentium PC, using the TDT software package SigPlay32. Stimuli were generated using a sample rate of $100 \mathrm{kHz}$ at 16-bit resolution. Equalization to correct for the system response was performed on the digital waveforms in the frequency domain. Acoustic stimuli ( $15 \mathrm{~ms}$ tone bursts, with $1.5 \mathrm{~ms}$ rise/fall times) were presented at 10 per second. TDT System II hardware and SigGen/Biosig software (TDT) were used to present the stimulus and record responses. Tones $(4,8,12$, and $16 \mathrm{kHz})$ were delivered through a Beyer driver (Beyer Dynamic; aluminum-shielded enclosure made in house), using a speculum placed just inside the tragus. Up to 1024 responses were averaged for each stimulus level. Responses were collected for stimulus levels in $10 \mathrm{~dB}$ steps at higher stimulus levels, with additional $5 \mathrm{~dB}$ steps near threshold. Thresholds were interpolated between the lowest stimulus level where a response was observed, and $5 \mathrm{~dB}$ lower, where no response was observed.

Deafening and tracer injections. Ten animals were anesthetized with intramuscular injections of ketamine hydrochloride (Ketaset; $40 \mathrm{mg} / \mathrm{kg}$ ) and xylazine (Rompun; $10 \mathrm{mg} / \mathrm{kg}$ ) and placed in a stereotaxic frame (David Kopf). Rectal temperature was maintained at $38^{\circ} \pm 0.5^{\circ} \mathrm{C}$ with a thermostatically controlled heating pad. Using a postauricular approach, a small incision was made behind the left ear and the skin retracted to expose the bulla. A small hole in the bulla was made and kanamycin (20 

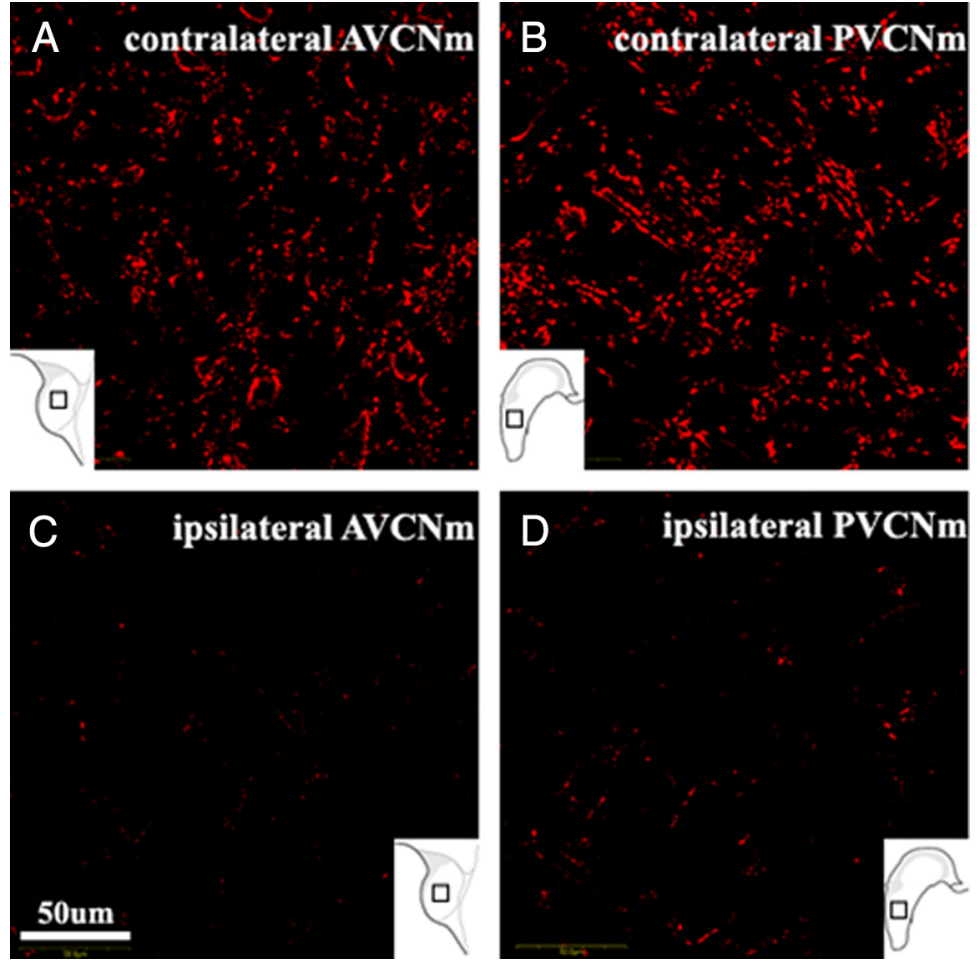

Figure 2. VGLUT1 immunostaining is decreased in the magnocellular regions of AVCN and PVCN after deafness. Photomicrographs of VGLUT1 are taken from the AVCN and PVCN of one animal (three weeks after deafening). VGLUT1 is intensely expressed in AVCN $(\boldsymbol{A})$ and PVCN $(\boldsymbol{B})$ in the contralateral side as shown previously (Zhou et al., 2007; Zeng et al., 2009), but weakly expressed following deafening $(\boldsymbol{C}, \boldsymbol{D})$.

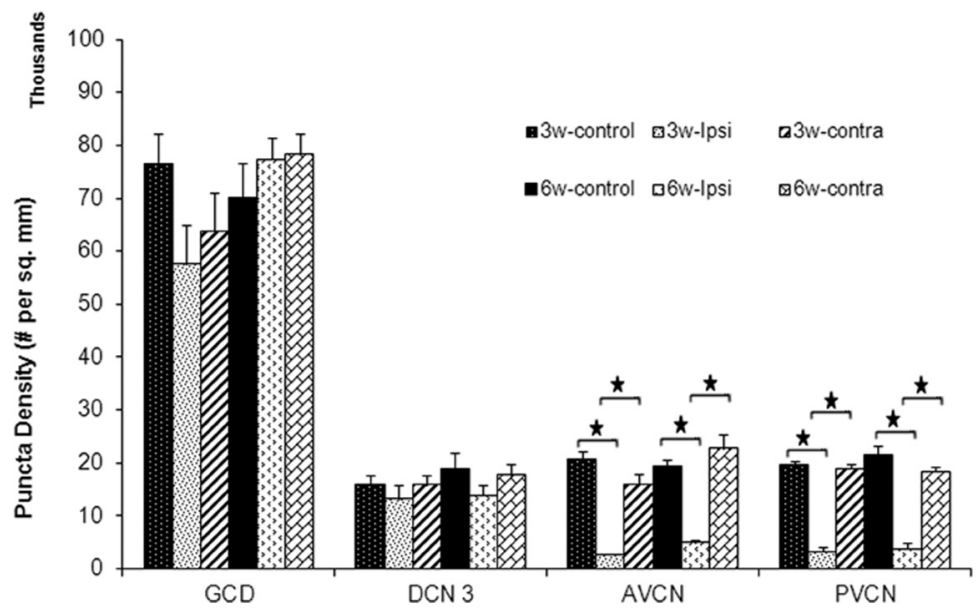

Figure 3. Mean VGLUT1 puncta densities in each CN subdivision in the ipsilateral side and contralateral side ( $N=3$ for each deafened animal group), as well as normal control CNs ( $N=4$ for each control group). VGLUT1 puncta densities (expressed as thousands/square $\mathrm{mm}$ ) are significantly decreased in the ipsilateral AVCN and PVCN, compared with both the contralateral and normal control CNs $(p<0.0001$, filled stars). Error bars represent SEM.

$\mu \mathrm{l}, 30 \%$ in normal saline) was injected into the cochlea using a Hamilton syringe, through the round window. After the injection, the skin overlying the bulla was sutured and the animal was allowed to recover.

Two weeks following deafening, two animals received anterograde tracers [ $10 \%$ biotinylated dextran-amine (BDA), MW 10,000, Invitrogen] in Sp5 and two animals received injections in $\mathrm{Cu}$, while four control animals likewise received identical tracer injections in $\mathrm{Sp} 5$ or $\mathrm{Cu}$. The surgical procedure has been described previously (Zhou and Shore, 2004; Zeng et al., 2011). Briefly, an opening just lateral-caudal to lambda was drilled in the occipital bone. A Hamilton microsyringe equipped with a glass micropipette (20-30 $\mu \mathrm{m}$ tip) was positioned into the left Sp5 (3 $\mathrm{mm}$ lateral to the midline, $2 \mathrm{~mm}$ caudal to the posterior edge of the transverse sinus, and $10.4 \mathrm{~mm}$ ventral to the surface of the dura) or the left $\mathrm{Cu}(1.8 \mathrm{~mm}$ lateral to the midline, $3 \mathrm{~mm}$ caudal to the posterior edge of the transverse sinus, and $8.8 \mathrm{~mm}$ ventral to the surface of the dura). A total volume of $0.1 \mu \mathrm{l}$ of anterograde tracer (BDA) was injected into the $\mathrm{Sp} 5$ or $\mathrm{Cu}$. After removing the pipette, the animals were sutured and allowed 1 week to recover.

Three weeks following deafening, final ABR measurements were performed in all deafened and control animals with tracer injection before being killed with FatalPlus (Vortech Pharmaceuticals; $5 \mathrm{mg} / \mathrm{kg}$, i.p.). Three deafened and two control animals without tracer injections also received ABRs and were killed. The animals were then perfused transcardially with $100 \mathrm{ml}$ of $0.1 \mathrm{M}$ PBS (pH 7.4), followed by $400 \mathrm{ml}$ of $4 \%$ paraformaldehyde in the same buffer. The brains were isolated and postfixed for $2 \mathrm{~h}$ at $4^{\circ} \mathrm{C}$, then transferred into $20 \%$ sucrose in $0.1 \mathrm{~m}$ phosphate buffer overnight at $4^{\circ} \mathrm{C}$. The brainstems were sectioned on a freezing microtome at a thickness of $40 \mu \mathrm{m}$; the cochleae were processed for spiral ganglion counts (see below).

Three deafened animals and two control animals survived for six weeks after deafening. Following final ABR measurements, the animals were killed and the brainstem and the cochleae were processed as above.

Spiral ganglion assessments. All deafened and control animals were processed for spiral ganglion counts. The density of spiral ganglion cells (SGCs) in the left (deafened) cochlea was compared with the right side and the control animals.

Differences in the number of spiral ganglion neurons (SGNs) were assessed as described previously (Zappia and Altschuler, 1989; Miller et al., 1997; Glueckert et al., 2008). Briefly, cochleae were rapidly removed following vascular fixation. Cochleae were then decalcified in 5\% EDTA and processed for embedding into JB-4 Plus, a glycol methacrylate plastic. Sections were cut at $5 \mu \mathrm{m}$ in a paramodiolar plane such that mid-modiolar sections had six cross-sectional profiles of Rosenthal's canal. Plastic sections were mounted on slides, stained with Paragon and coverslipped. The 12 most mid-modiolar sections were selected and every third section was used for quantitative assessment to reduce the chance of counting a cell twice. Digital images of the entire most basal cross sectional profile through Rosenthal's canal were acquired under bright field optics and exported to a MetaMorph Image Analysis workstation. An image of the profile through Rosenthal canal was also acquired at a lower magnification and the outline circled to give an area that could be used to generate a measure for SGN density within that profile. The area of Rosenthal's canal on every third section was measured and the number of spiral ganglion neuron profiles counted. The criteria for inclusion as a spiral ganglion neuron included having a round cell body (aspect ratio of length to width 3:1) diameter between 14-20 $\mu \mathrm{m}$, the presence of a nucleus with a diameter between 7-10 $\mu \mathrm{m}$, and a homogenous cytoplasm. The use of these criteria minimized the potential for over- or underestimating the number of spiral ganglion cells that can occur when counting cell profiles due to, for example, surviving neurons changing their size significantly.

Brain tissue and immunocytochemistry processing. Forty micrometer transverse sections of the brainstem were cut and mounted in four series 
on clean glass slides and air-dried. Two serial sections without tracer injections were used to label VGLUT1 or VGLUT2 only, the two other series were saved as back-up. For the sections with tracer injections, one series was used to label BDA and VGLUT1, one was used to label BDA and VGLUT2, and the third series was labeled with only BDA for injection location definition and projection puncta counting. The final series was saved for back-up. To define the injection size and location, all sections in the third series containing the injected tracer were photographed using a fluorescent microscope equipped with a digital camera (Leica, DM). The images were imported to Photoshop and the borders of the injection site were traced and cropped. The cropped images were exported to MetaMorph for measuring the areas. The volume of each injection site was calculated by summing the injection areas and multiplying by $120 \mu \mathrm{m}$, the separation between two contiguous sections (Moore and Kowalchuk, 1988). This analysis yielded two pairs of size and location-matched Sp5 injections (two controls, two three-week deafened) and two pairs of $\mathrm{Cu}$ injections (two controls, two threeweek deafened).

The VGLUT1 and VGLUT2 immunocytochemistry procedure used here has been described previously (Zhou et al., 2007; Zeng et al., 2009). Briefly, all tissue processing was done at room temperature $\left(20-22^{\circ} \mathrm{C}\right)$. Sections were incubated for $30 \mathrm{~min}$ in a blocking solution containing $1 \%$ normal goat serum in 0.1 M PBS with $0.1 \%$ Triton X-100, PH 7.4, followed by overnight incubation with primary antibodies, VGLUT1 (polyclonal antibody, generated in rabbit, diluted in 1:1000, Synaptic Systems, Cat. \#135 303) or VGLUT2 (polyclonal antibody, generated in rabbit, diluted in 1:1000, Synaptic Systems, Cat. \#135 403). After thoroughly rinsing in PBS, sections were reacted with the secondary antibody (Alexa Fluor 555-conjugated goat anti-rabbit; Invitrogen) for $2 \mathrm{~h}$. After rinsing, slides were dehydrated in graded ethanol and coverslipped using microcover gel (Micron Diagnostics). Negative controls were conducted on sections that were not treated with either primary or secondary antibodies, resulting in no immunolabeling. VGLUT antibodies were preincubated with corresponding synthetic peptides (Strep-Tag fusion protein containing amino acid residues $456-$ 560 of rat VGLUT1, Cat. \# 135-3P, or Strep-Tag fusion protein containing amino acid residues 510-582 of rat VGLUT2, Cat. \# 135-4P, Synaptic Systems), resulting in negative immunolabeling. Western blots previously performed (Zhou et al., 2007) demonstrated anti-VGLUT1 antibody with a single band at $\sim 60 \mathrm{kDa}$ on protein extracted from both $\mathrm{CN}$ and cerebellum and anti-VGLUT2 antibody as a single band at $\sim 65 \mathrm{kDa}$, corresponding to the molecular weights predicted for VGLUT1 and VGLUT2, respectively. Positive controls for VGLUT were performed in the cerebellar cortex (Takamori et al., 2001; Kaneko et al., 2002; Hioki et al., 2003). To visualize BDA-labeled Sp5 and Cu terminals colabeled with VGLUT, sections were incubated for $2 \mathrm{~h}$ with $\mathrm{Cy} 2$ conjugated with streptavidin (1:300, Jackson ImmunoResearch), followed by immunolabeling with VGLUT1 or VGLUT2.

Image processing. Sections were examined using a fluorescent microscope equipped with the appropriate filters for Alexa 555 and Cy2 (Leica, DM). Photomicrographs of immunolabeling were imported to Adobe Photoshop for contrast adjustment, then digitized and imported to
MetaMorph for quantification. The parameters for digitizing photomicrographs were kept constant across all animals (Zhou et al., 2007; Zeng et al., 2009). Images of VGLUT were taken for all subdivisions of the CN, including DCN1, DCN3, GCD (Shell region and DCN2), anteroventral cochlear nucleus (AVCN), and posteroventral cochlear nucleus (PVCN). Within a slice series, each region of the $\mathrm{CN}$ had three images taken to create an average puncta density for that subdivision. To focus on changes in nonauditory inputs, the puncta density of the shell region and DCN2 were combined to yield the GCD density. The GCD has been previously defined as the combined shell and fusiform cell layer regions (DCN2) (Zhou et al., 2007), which receive primarily nonauditory inputs. The VGLUT densities in DCN1, DCN3, GCD, AVCN, and PVCN in each group were then compared between the control and deafened groups (Zeng et al., 2009).

Quantification and analysis of VGLUT and tract tracing projection terminals. Quantification was performed as previously described (Zhou et al., 2007; Zeng et al., 2009). Experimenters were blind as to whether the tissue was from normal or deafened animals. VGLUT density was quantified in each of the following CN regions: DCN1, DCN3, GCD, AVCN, and PVCN. Sections for AVCN and PVCN were taken from the middle- 


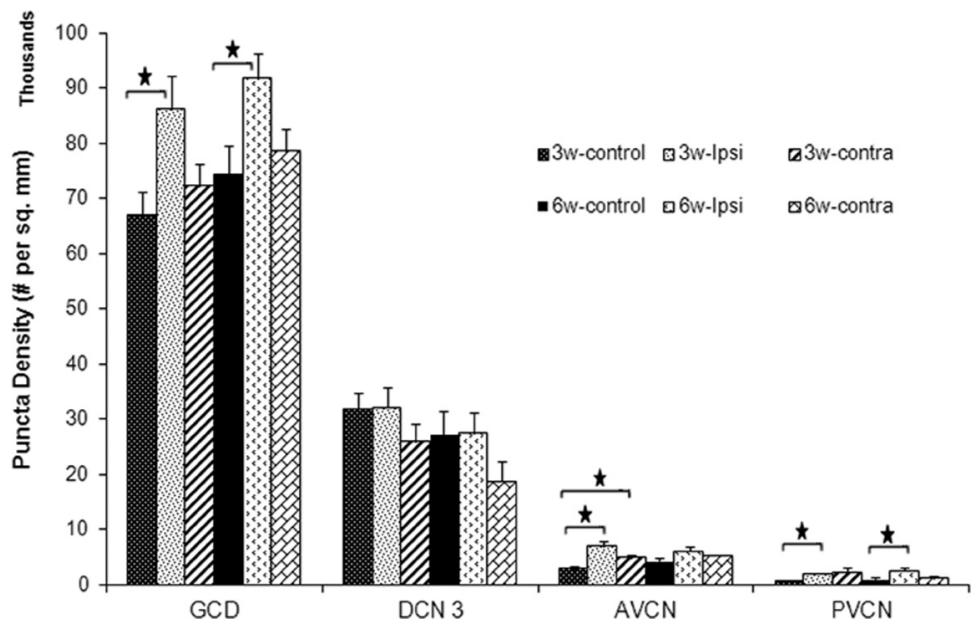

Figure 5. Mean VGLUT2 puncta densities in each CN subdivision in the ipsilateral side and contralateral side ( $N=3$ for each deafened animal group), as well as normal control CNs ( $N=4$ for each control group). VGLUT2 puncta densities (expressed as thousands/square $\mathrm{mm}$ ) are significantly increased in the ipsilateral GCD that receives nonauditory synaptic terminals (Zhou et al., 2007). VGLUT2 puncta densities are also significantly increased in ipsilateral magnocellular regions (AVCN and PVCN), which also receive some nonauditory inputs from Sp5 and cuneate nucleus (Zeng et al., 2011), compared with both the contralateral and normal control CNs ( $p<0.05$, filled stars). Error bars represent SEM.

frequency regions (i.e., halfway between the most dorsal aspect and the most ventral aspect of the VCN). This method thereby encompassed regions affected by the hearing loss. For each side of each animal, three pictures $(40 \times)$ were taken at equal intervals from caudal to rostral for each of the above selected regions except DCN1 (i.e., one picture from the 25 th percentile, one from the 50th percentile, and one from the 75 th percentile, etc.). For DCN1, a higher magnification $(63 \times)$ was used. The photomicrographs were then transferred to MetaMorph for automatic quantification. The total number of VGLUT labeled puncta was divided by the chosen area in each photomicrograph to yield the puncta density. No distinction was made between puncta on cell bodies and puncta on dendrites or in the neuropil. Means and SEs were calculated for the puncta density of VGLUT1 and VGLUT2. The deafened side was compared with the contralateral side and age-matched normal controls.

Under epifluorescence, the labeled $\mathrm{Cu}$ and $\mathrm{Sp} 5$ terminals in both $\mathrm{CN}$ were manually counted on every section of one series in each group. The quantification was based on terminals in both CNs unless otherwise stated. $\mathrm{Cu}$ and $\mathrm{Sp} 5$ terminal endings were further classified as follows: (1) mossy fiber-like terminal endings (MFs): large irregular swellings ( $\geq 2.5$ $\mu \mathrm{m}$ ), which usually give rise to collaterals; or (2) small boutons (SBs): small and round or oval $(<2.5 \mu \mathrm{m})$, including en passant and terminal boutons (Zhou and Shore, 2004; Zeng et al., 2011). Each ending was defined by size, location in the CN, and double labeling with VGLUT1/ VGLUT2. Double labeling of $\mathrm{Cu}$ and Sp5 terminals with VGLUTs were determined by frequently switching the filters and adjusting the focus of the objective lens. Colocalization was established when the two different labels (red and green) exactly marked the same profile at the same focusing level. In many cases, double-labeled immunofluorescent terminals were also identified by confocal laser microscopy (Olympus 500). The method of identifying double-labeled Cu/Sp5-VGLUT1/VGLUT2 terminals in the $\mathrm{CN}$ corresponded well with the confocal findings. For both $\mathrm{Cu}$ and Sp5 terminals, there were four categories: (1) SB-non-colabeled with VGLUT1/VGLUT2; (2) SB-colabeled with VGLUT1/VGLUT2; (3) MF-non-colabeled with VGLUT1/VGLUT2; (4) MF-colabeled with VGLUT1/VGLUT2. The terminal counts were obtained from the first series of sections and the number of terminal counts was multiplied by 4 to achieve the total terminal counts. Finally, Abercrombie's correction was used to adjust possible double counting errors: corrected number $=$ count $\times$ [section thickness/(section thickness + terminal size)] (Abercrombie, 1946). For the unilaterally deafened animals, the contralateral and the ipsilateral CNs were compared to each other and to the normal controls. Statistical analyses were performed using one-way ANOVA, $t$ test or $\chi^{2}$, as appropriate. Significance was determined at $p<0.05$.

\section{Results}

Unilateral injections of kanamycin resulted in profound, unilateral hearing loss after three and six weeks following deafening

All 10 animals with unilateral intracochlear injections of kanamycin had profound, unilateral hearing losses as demonstrated with ABR measurements (Fig. 1A). No ABR responses were measurable at $90 \mathrm{~dB}$ SPL (the limits of our sound system) in the deafened ears. Figure $1 A$ shows the mean ABR thresholds for the deafened animals at four test frequencies $(4,8,12$, and $16 \mathrm{kHz})$ for the left (ipsilateral, deafened) ears before and after deafening, as well as 16 normal control ears in the eight normal hearing animals.

\section{Spiral ganglion density is significantly reduced three and six weeks following deafening}

Figure $1 B$ shows the mean spiral ganglion densities for the whole cochlea as well as the basal turn at three and six weeks following deafness. The left side (ipsilateral to deafening) for the whole cochlea $(F=219.74 ; \mathrm{df}=2,15 ; p<0.001)$ and the basal turn $(F=107.89 ;$ $\mathrm{df}=2,15 ; p<0.001)$ shows significantly decreased spiral ganglion density when compared with the control animals and the right ears at both three and six weeks. Figure $1 C$ shows the normal appearance of spiral ganglion cells in one control animal, and Figure $1 D$ shows the significant loss of spiral ganglion cells in one animal after three weeks deafness. Thus, after unilateral deafness (three and six weeks), spiral ganglion densities are reduced significantly compared with the contralateral (right) side and the control groups. Spiral ganglion densities of the contralateral ear were not significantly different between the three and six week groups and the control animals, similar to those previously reported (Miller et al., 2007; Zeng et al., 2009).

\section{VGLUT expression is significantly altered in the cochlear} nuclei three and six weeks after unilateral deafening

(1) Along with decreased SG density, VGLUT1 density was significantly decreased in the VCN ipsilateral to the cochlear injections three and six weeks after unilateral deafness.

Compared with both the control and contralateral data, significant decreases in VGLUT1 labeling were seen in the AVCN and PVCN. Figure 2 shows photomicrographs of decreased VGLUT1 density in the ipsilateral AVCN and PVCN in one animal (three weeks after deafening) in comparison with the contralateral side. The photomicrographs in Figure 2, $A$ and $B$, show strong VGLUT1 labeling in the contralateral AVCN and PVCN, whereas sparse VGLUT1 labeling was observed on the side ipsilateral to the deafening (Fig. 2C,D). Compared with both the contralateral $\mathrm{CN}$ and normal controls, quantification reveals that ipsilateral VGLUT1 densities were significantly decreased in ipsilateral VCN (AVCN and PVCN) after three (Fig. 3, $F=29.51$; $\mathrm{df}=2,24 ; p<0.001$ for AVCN, $F=87.87 ; \mathrm{df}=2,24 ; p<0.001$ for PVCN) and six weeks of deafness (Fig. $3, F=34.46$; $\mathrm{df}=2$, 24; $p<0.001$ for AVCN, $F=53.78 ; \mathrm{df}=2,24 ; p<0.001$ for PVCN). No significant change in VGLUT1 was found in other regions of $\mathrm{CN}$, including DCN1 (not shown in the figure).

(2) VGLUT2 density was increased in the ipsilateral GCD, which is the primary recipient of nonauditory inputs. In addition, VGLUT2 is also increased in the ipsilateral magnocellular regions 

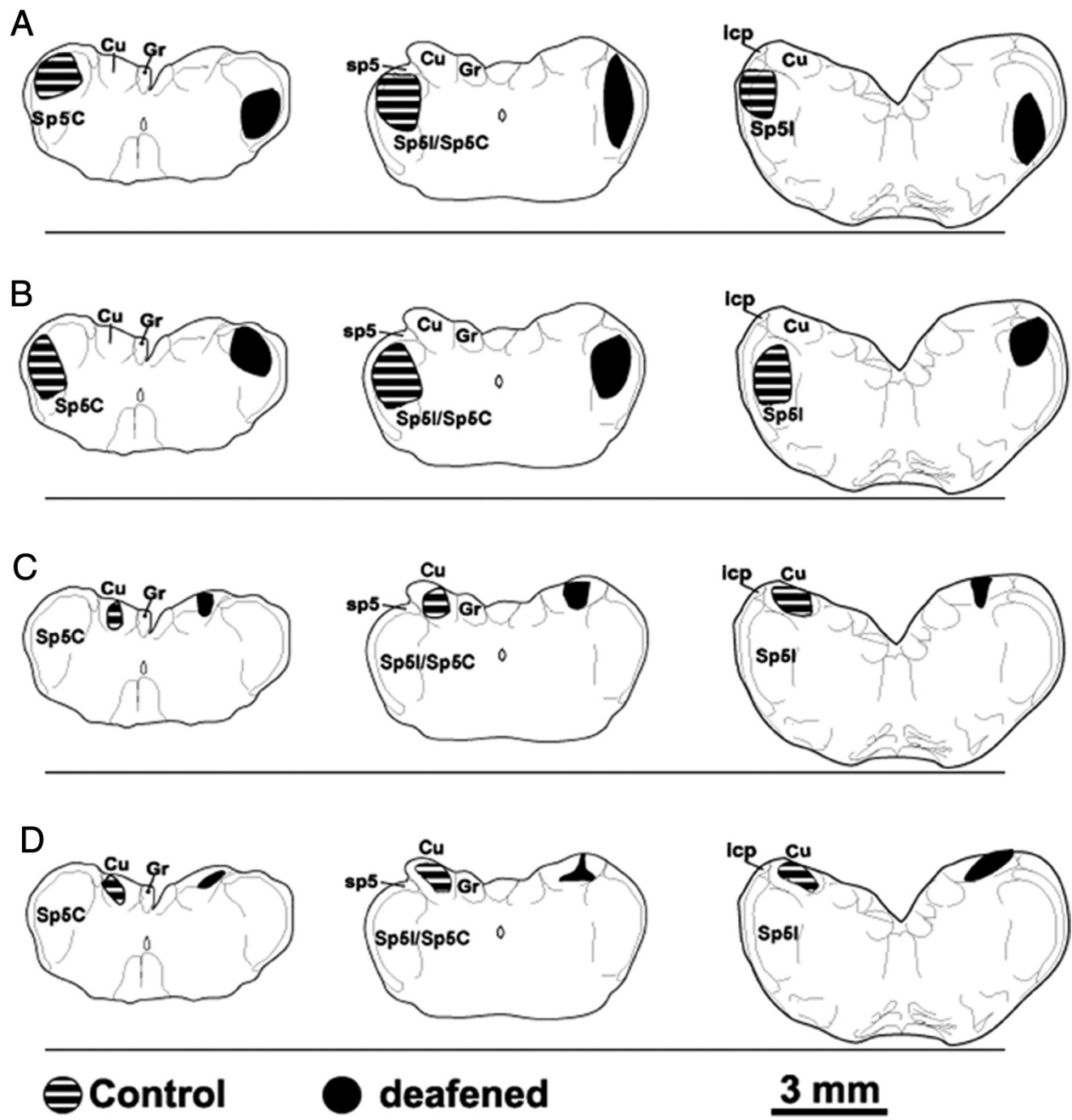

Figure 6. Locations of the injection sites in matched control and deafened animals are shown on drawings of caudal to rostral transverse brainstem sections. The cross-hatched areas represent the injection sites in control guinea pigs, the solid shaded areas represent the injection sites in deafened guinea pigs. $A$, Three serial sections of matched pairs of $S p 5$ injections in one control animal (solid; volume $=3.56 \mathrm{~mm}^{3}$ ) and one deafened animal (hatched, volume $=2.81 \mathrm{~mm}^{3}$ ). $\boldsymbol{B}$, A second pair of matched Sp5 injections in one control animal (solid; volume $=2.19 \mathrm{~mm}{ }^{3}$ ) and one deafened animal (hatched; volume $=1.26 \mathrm{~mm}^{3}$ ). C, Matched Cu injections in one control animal (solid; volume $=0.49 \mathrm{~mm}^{3}$ ) and one deafened animal (hatched; volume $=0.44 \mathrm{~mm}{ }^{3}$ ). $\boldsymbol{D}, \mathrm{A}$ second matched pair of Cu injections in one control animal (solid; volume $=0.67 \mathrm{~mm}^{3}$ ) and one deafened animal (hatched; volume $=0.68 \mathrm{~mm}^{3}$ ). The injection sizes in two control animals with Sp5 injections are slightly larger than the matched deafened counterparts, while two pairs with Cu injections have very similar injection sizes. All injections occurred on the left side of the brain but are shown here for convenience of separation on both sides. sp5, Spinal trigeminal tract; Sp51, pars interpolaris of Sp5; Sp5C, pars caudalis of Sp5; icp, inferior cerebellar peduncle; Gr, gracile nucleus.

of VCN that predominantly receive auditory inputs at both three and six weeks after unilateral deafness.

Although VGLUT2 is intensely expressed in the GCDs of both normal controls and deafened guinea pigs (Zhou et al., 2007; Zeng et al., 2009), it is significantly increased in the ipsilateral GCD of unilaterally deafened animals starting at two weeks following deafening (Zeng et al., 2009), and shown here also at three and six weeks following unilateral deafening. Figure 4 shows photomicrographs of increased VGLUT2 density in the ipsilateral GCD (Fig. 4A) of one animal (three weeks after deafening) compared with the contralateral side (Fig. 4D). There is sparse VGLUT2 labeling in the contralateral AVCN and PVCN (Fig. $4 E, F)$, but stronger VGLUT2 expression in the ipsilateral AVCN and PVCN (Fig. $4 B, C$ ). Compared with control animals, there is an upregulation of VGLUT2 in the ipsilateral GCD three $(F=$ 4.19; $\mathrm{df}=2,24 ; p<0.05)$ and six weeks $(F=4.00 ; \mathrm{df}=2,24 ; p<$ $0.05)$ following deafening. VGLUT2 densities in ipsilateral AVCN and PVCN are significantly increased at three weeks following deafening (Fig. 5; $F=10.32$; df $=2,24 ; p<0.001$ for AVCN, $F=8.04 ; \mathrm{df}=2,24 ; p<0.05$ for PVCN). VGLUT2 increases were also seen in the ipsilateral PVCN at six weeks after deafness when compared with control animals $(F=4.18$; $\mathrm{df}=2$, $24 ; p<0.05)$.

Thus, following unilateral deafening, VGLUT2 was significantly increased in regions of the GCD that receive somatosensory inputs and was also increased in the ipsilateral magnocellular region of $\mathrm{CN}$. No significant changes were seen in DCN1 and DCN3.

\section{Somatosensory inputs are upregulated and redistributed three weeks following deafening}

Four guinea pigs (two controls, two three-week deafened) received BDA injections restricted to $\mathrm{Sp} 5$, and four guinea pigs (two controls, two three-week deafened) received BDA injections restricted to $\mathrm{Cu}$. The locations of all eight injection sites are summarized in serial brainstem templates in Figure 6 . The injection sites and volumes were well matched in the deafened and control animals. The first pair of matched Sp5 injections ( $A$, top row) shows a slightly larger injection site in the control animal (volume $=3.56 \mathrm{~mm}^{3}$ ) than the deafened animal $(2.81$ 
$\left.\mathrm{mm}^{3}\right)$. The second pair of matched Sp5 injections ( $B$, second row) has a smaller injection size than the first pair, but also shows a slightly larger injection in the control animal (volume $=2.19 \mathrm{~mm}^{3}$ ) than the deafened animal (volume $=1.26$ $\mathrm{mm}^{3}$ ). All 4 Sp5 injections are restricted to the Sp5. The two pairs of $\mathrm{Cu}$ injections (bottom rows, $C$ and $D$ ) have very similar injection volumes, with one control animal $(C$, solid, volume $\left.=0.49 \mathrm{~mm}^{3}\right)$ paired with one deafened animal $(C$, hatched, volume $=0.44 \mathrm{~mm}^{3}$ ), and a second control animal $\left(D\right.$, solid, volume $\left.=0.67 \mathrm{~mm}^{3}\right)$ paired with another deafened animal $\left(D\right.$, hatched, volume $\left.=0.68 \mathrm{~mm}^{3}\right)$.

Even though the injection sites and volumes were well matched in the deafened and control animals, to help further interpret the changes in $\mathrm{Sp} 5$ and $\mathrm{Cu}$ projections to the $\mathrm{CN}$ with hearing loss, the means and SEs of the means were computed for the number of projection terminals in both deafened and control animals. The results depicted in Figure 7 show little variation in the amount of $\mathrm{CN}$ labeling between control and deafened animals. The projection counts are further divided into those colocalized with VGLUT2 and those not colocalized in Figure 8. The results in Figures 7 and 8 reveal that three weeks following unilateral deafening, there was a significant increase in the numbers of both $\mathrm{Sp} 5$ and $\mathrm{Cu}$ projection terminals in almost every region in the $\mathrm{CN}$ compared with control animals. The terminal distributions of $\mathrm{Sp} 5$ and $\mathrm{Cu}$ projections in control and deafened guinea pigs were all bilateral with ipsilateral dominance, with most of these terminals located predominantly in the GCD, which receives somatosensory inputs. However, the distribution patterns were differentially altered depending on the projection source. In control animals, the total number of $\mathrm{Cu}$ projection terminals was considerably less than the number of Sp5 projections ( $p<0.05$, two-tailed $t$ test). Cu projections were located primarily in the $\mathrm{GCD}$ with a minor presence in $\mathrm{DCN} 3$, while Sp5 projections were located primarily in the GCD with a broader distribution in DCN3, AVCN, and PVCN. In deafened animals, the total numbers of both $\mathrm{Cu}$ and $\mathrm{Sp} 5$ projections increased, but the total number of $\mathrm{Cu}$ projections remained lower than Sp5 projections $(p<0.05$, two-tailed $t$ test). Furthermore, the distributions of projection terminals from $\mathrm{Cu}$ and $\mathrm{Sp} 5$ were changed differently after three weeks unilateral deafness. Despite a predominant distribution in the GCD, $\mathrm{Cu}$ projections were increased in DCN3 and VCN while Sp5 projections were increased in VCN. These data indicate that three weeks following deafening, the $\mathrm{CN}$ received increased numbers of projections from both $\mathrm{Cu}$ and $\mathrm{Sp} 5$. Furthermore, these increases were observed not only in the GCD, which receives somatosensory inputs, but also in the non-GCD regions, DCN3 and VCN (Figs. $7 A, B, 8 A, B$ ).

Additionally, the morphological patterns of projection terminals were altered differentially depending on the source (Fig. $8 \mathrm{C}-$ $F$ ). As shown previously (Zeng et al., 2011), Cu and Sp5 terminal endings are either MFs or SBs. In control animals, the MF-to-SB ratio for $\mathrm{Cu}$ terminals was 1:2.3, while the MF-to-SB ratio for Sp5 terminals was $1: 9\left(\chi^{2}, p<0.001\right)$. In deafened guinea pigs, the MF-to-SB ratio of $\mathrm{Cu}$ terminals decreased to 1:4 compared with control animals $\left(\chi^{2}, p<0.01\right)$, while the ratio for $\mathrm{Sp} 5$ terminals increased to 1:5 compared with control animals $\left(\chi^{2}, p<0.001\right)$. Thus, there was a greater increase in $\mathrm{Cu}$ SBs but a greater increase in Sp5 MFs compared with control animals (Fig. 8C-F).

The colocalization of Sp5 and Cu projections with VGLUT2 changes three weeks following deafening

$\mathrm{Sp} 5$ and $\mathrm{Cu}$ terminal endings in CN colabel with VGLUT2 but rarely with VGLUT1 (Zhou et al., 2007; Zeng et al., 2011). In the

\section{A Sp5 projections in the $\mathrm{CN}$ before and after deafness}

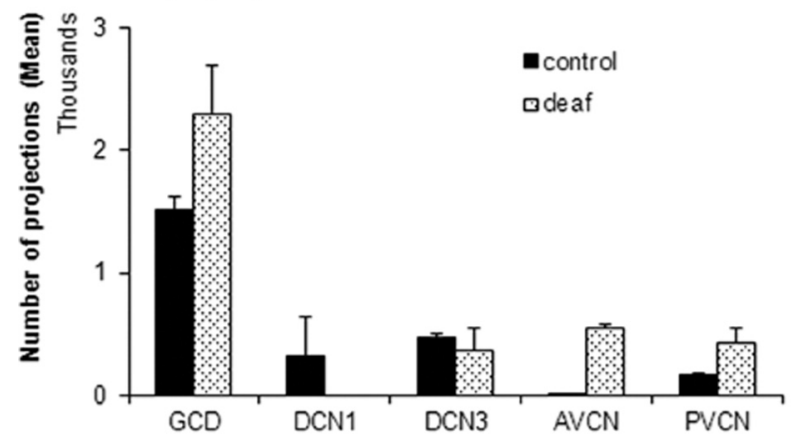

B Cu projections in the $\mathrm{CN}$ before and after deafness

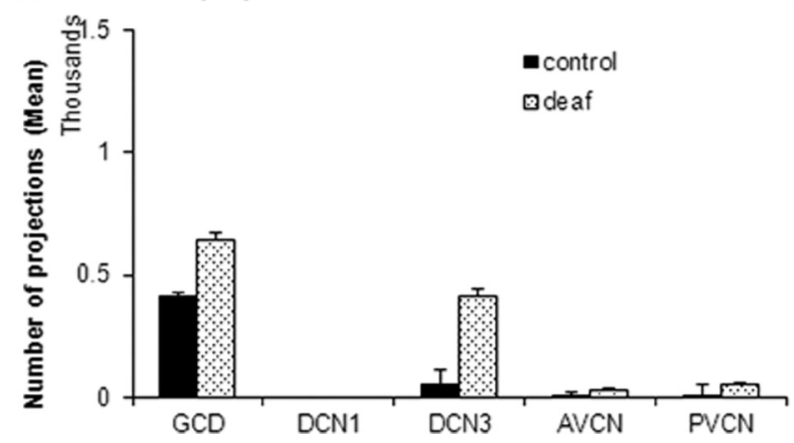

Figure 7. Means and SEs of the means for $\mathrm{Cu}$ and Sp5 terminal endings in different subdivisions of the $\mathrm{CN}$ in control ( $\mathrm{Cu}, N=2 ; \mathrm{Sp} 5, N=2)$ and deafened ( $\mathrm{Cu}, N=2 ; \mathrm{Sp} 5, N=2)$ guinea pigs. There was little variation in the amount of $C N$ labeling between control and deafened animals. $\boldsymbol{A}$, Sp5 terminals were mostly located in the GCD, with increases seen in the GCD and VCN in the deafened animals. $B$, Cu terminal endings were mostly located in the $G C D$, with increases seen in the GCD and DCN3 in deafened animals.

present study, we examined the association of Sp5 and $\mathrm{Cu}$ projection terminals with VGLUT2 in deafened guinea pigs compared with control animals (Fig. 8). Three weeks following deafening, VGLUT2-colabeled $\mathrm{Cu}$ and Sp5 terminals were significantly increased in the CN compared with control animals $(p<$ 0.01 , two-tailed $t$ test for $\mathrm{Cu} ; p<0.001$, two-tailed $t$ test for Sp5; Fig. $8 A, B)$. In control animals, most of the VGLUT2-labeled $\mathrm{Cu}$ and Sp5 terminals were located in the GCD. In the deafened animals, whileVGLUT2-labeled $\mathrm{Cu}$ and Sp5 terminal numbers still predominated and increased in the GCD, they also increased in DCN3 and VCN. Indeed, there were greater increases in VGLUT2-labeled Cu terminals in DCN3 $\left(\chi^{2}, p<\right.$ $0.001)$ and increased numbers of VGLUT2-labeled Sp5 terminals in $\operatorname{VCN}\left(\chi^{2}, p<0.001\right)$, than in GCD alone. These changes are consistent with recently reported increased VGLUT2-mediated vestibular inputs to the DCN (Barker et al., 2012) after acoustic overexposure.

The distribution patterns of VGLUT2-labeled MFs and SBs from $\mathrm{Cu}$ and $\mathrm{Sp} 5$ were also changed following three weeks of deafening. Most MFs colabeled with VGLUT2, and were located predominantly in the GCD in both control and deafened guinea pigs for both $\mathrm{Cu}$ and $\mathrm{Sp} 5$ terminals (Figs. $8 C-F, 9,10$ ). While $\mathrm{Cu}$ and Sp5 SBs were also GCD dominant, fewer SBs colabeled with VGLUT2 than MFs. In the deafened animals, VGLUT2-labeled $\mathrm{Cu}$ and Sp5 MFs retained GCD predominance. VGLUT2-labeled $\mathrm{Cu}$ SBs increased in DCN3 $\left(\chi^{2}, p<0.001\right)$ (Figs. 8, 9), and VGLUT2-labeled Sp5 SBs increased in the VCN $\left(\chi^{2}, p<0.001\right)$ (Figs. 8, 10). VGLUT2-labeled SBs from Sp5 were the main contributors to the increase in VGLUT2 in the ipsilateral VCN fol- 
A

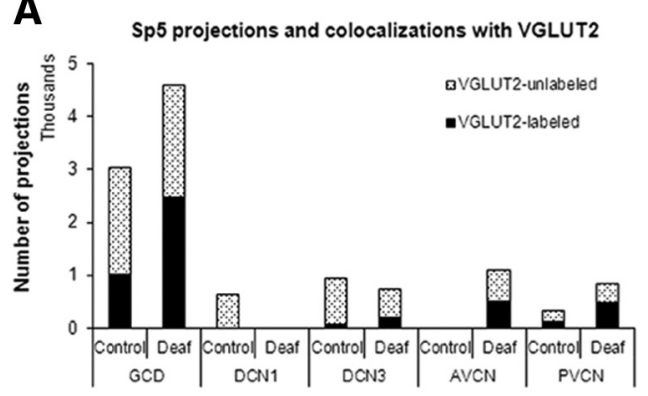

B

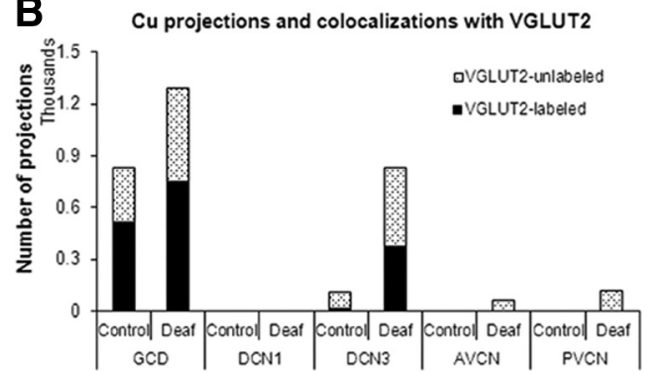

C
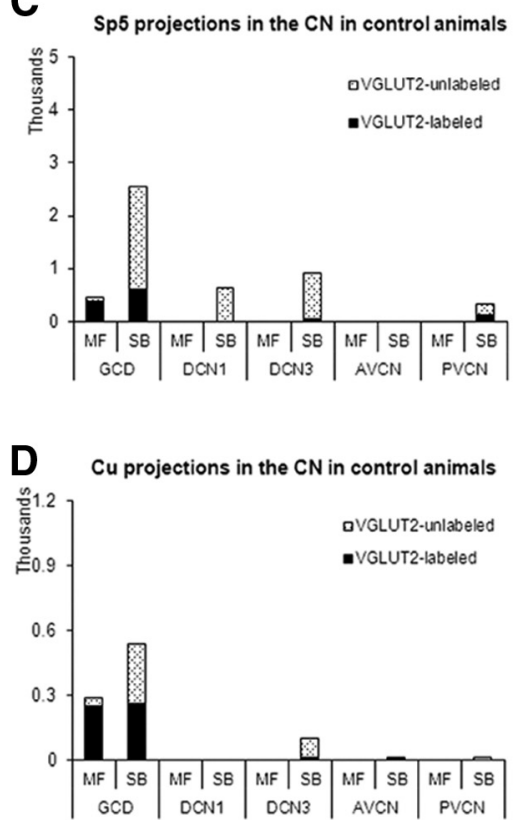
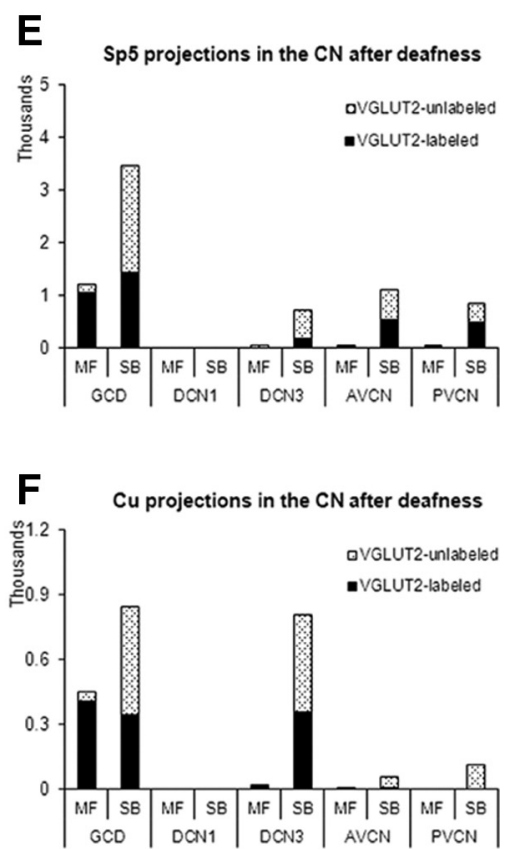

Figure 8. Counts of labeled $\mathrm{Cu}$ and Sp5 terminal endings colocalized and not colocalized with VGLUT2 in different subdivisions of the $\mathrm{CN}$ in control $(\mathrm{Cu}, N=2 ; \mathrm{Sp} 5, N=2)$ and deafened ( $C u, N=2 ; S p 5, N=2)$ guinea pigs. $A$, VGLUT2-labeled Sp5 terminals were mostly located in the GCD, with increases seen in the GCD and VCN in the deafened animals. $B$, VGLUT2-labeled Cu terminal endings were mostly located in the GCD, with increases seen in the GCD and DCN3 in deafened animals. C, E, VGLUT2-labeled Sp5 MFs and SBs significantly increased in the GCD and VCN in the deafened animals. $D, F$, Numbers of VGLUT2-labeled Cu MFs and SBs significantly increased in the GCD and DCN3 in deafened guinea pigs, some VGLUT2-labeled MFs were seen in the VCN.
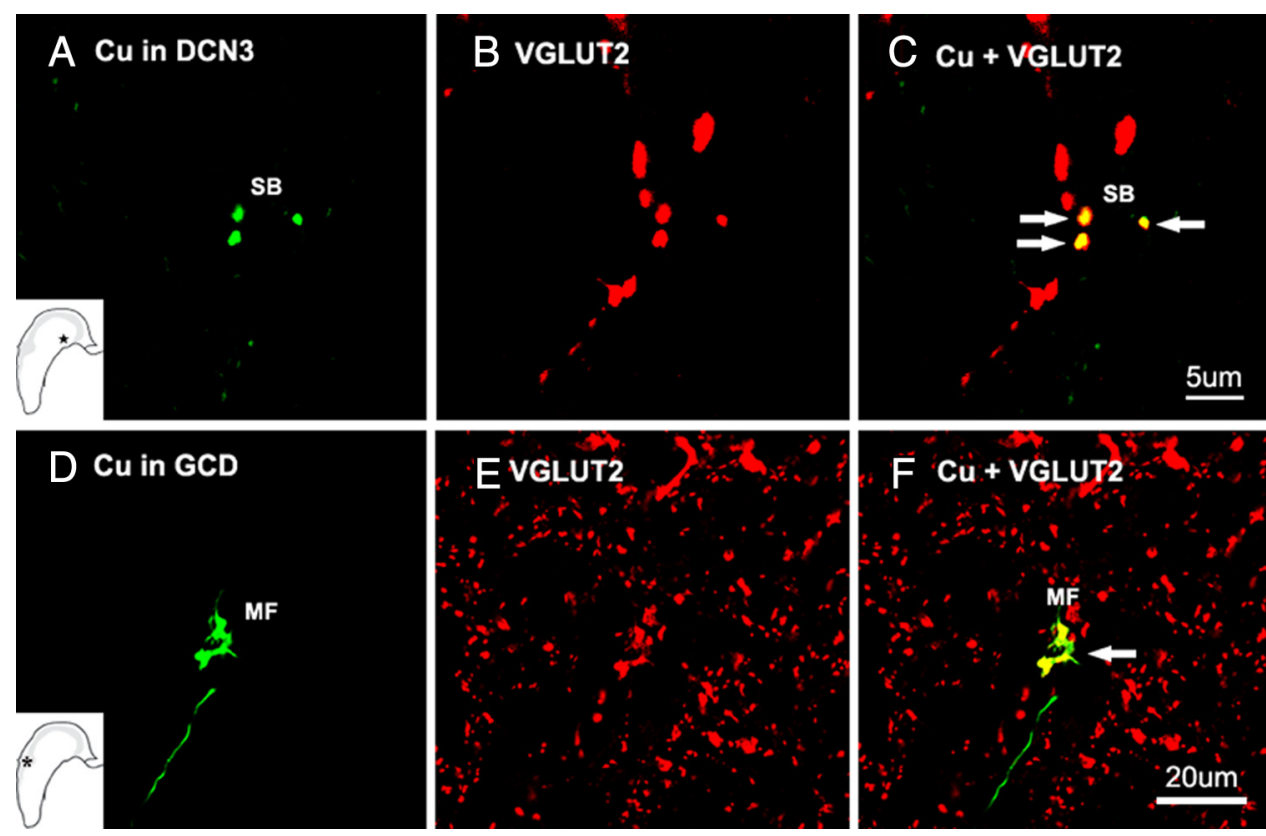

Figure 9. High-magnification confocal images $(\times 100)$ showing colocalization of anterogradely labeled Cu terminal endings with VGLUT2 in DCN3 $(\boldsymbol{A}-\boldsymbol{C})$ and GCD (D-F) in a 3-week-deafened guinea pig, the terminal locations are designated by the asterisks in the insets. $\boldsymbol{A}$ and $\boldsymbol{D}$ show BDA-labeled Cu terminals (green), $\boldsymbol{B}$ and $\boldsymbol{E}$ show VGLUT2 labeling (red). Colocalization of VGLUT2 with Cu SBs in DCN3 is shown by arrows in C, and colocalization of VGLUT2 with Cu MFs in GCD is shown by arrow in $\boldsymbol{F}$. Scale bars: $A-C, 5 \mu \mathrm{m} ; \boldsymbol{D}-\boldsymbol{F}, 20 \mu \mathrm{m}$.

lowing deafness. In addition to an increased number of VGLUT2-labeled SBs, deafened animals exhibited more VGLUT2-labeled MFs than control animals $(p<0.001$; Figs. 8 , $10)$. While there were fewer Sp5-labeled MFs in the VCN than in the GCD, their appearance in the VCN suggest that a different form of neural processing may occur three weeks after unilateral deafness.
The colocalization of Sp5 and Cu projections with VGLUT1 is altered three weeks following deafening

Compared with VGLUT2, there were considerably fewer $\mathrm{Cu}$ and Sp5 terminals colabeled with VGLUT1 in both control and deafened guinea pigs (Fig. 11). VGLUT1-labeled Cu and Sp5 endings were GCD predominant in both control and deafened animals. Although VGLUT1-labeled $\mathrm{Cu}$ and Sp5 terminals constitute a 

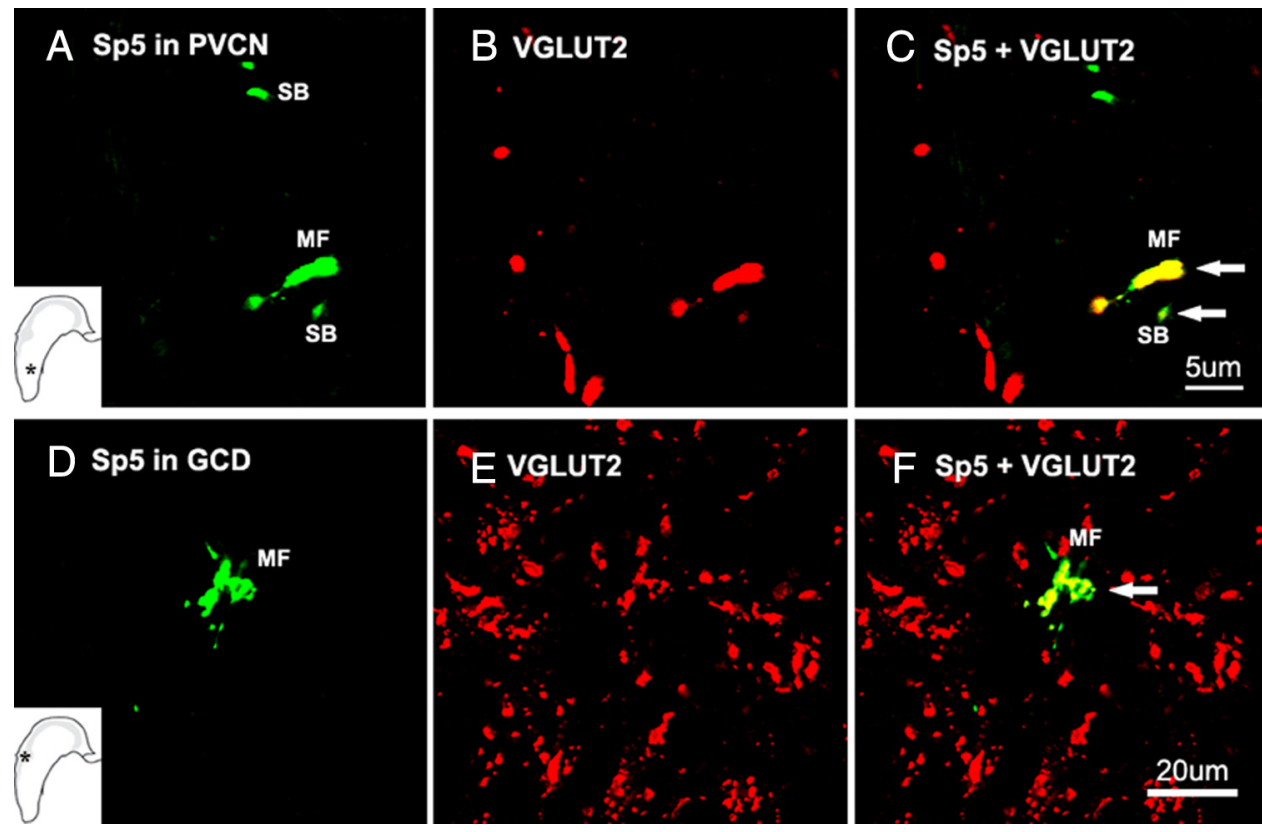

Figure 10. High-magnification confocal images $(\times 100)$ showing colocalization of anterogradely labeled Sp5 terminal endings with VGLUT2 in PVCN $(\boldsymbol{A}-\boldsymbol{C})$ and GCD $(\boldsymbol{D}-\boldsymbol{F})$ in a 3 -week-deafened guinea pig, the terminal locations are designated by the asterisks in the insets. $\boldsymbol{A}$ and $\boldsymbol{D}$ show BDA-labeled Sp5 terminals (green), $\boldsymbol{B}$ and $\boldsymbol{E}$ show VGLUT2 labeling (red). Colocalization of VGLUT2 with Sp5 SBs and MFs in PVCN is shown by arrows in $\boldsymbol{C}$, and colocalization of VGLUT2 with Sp5 MFs in GCD is shown by arrow in $\boldsymbol{F}$. Scale bars: $\boldsymbol{A}-\boldsymbol{C}, 5 \mu \mathrm{m} ; \boldsymbol{D}-\boldsymbol{F}, 20 \mu \mathrm{m}$.
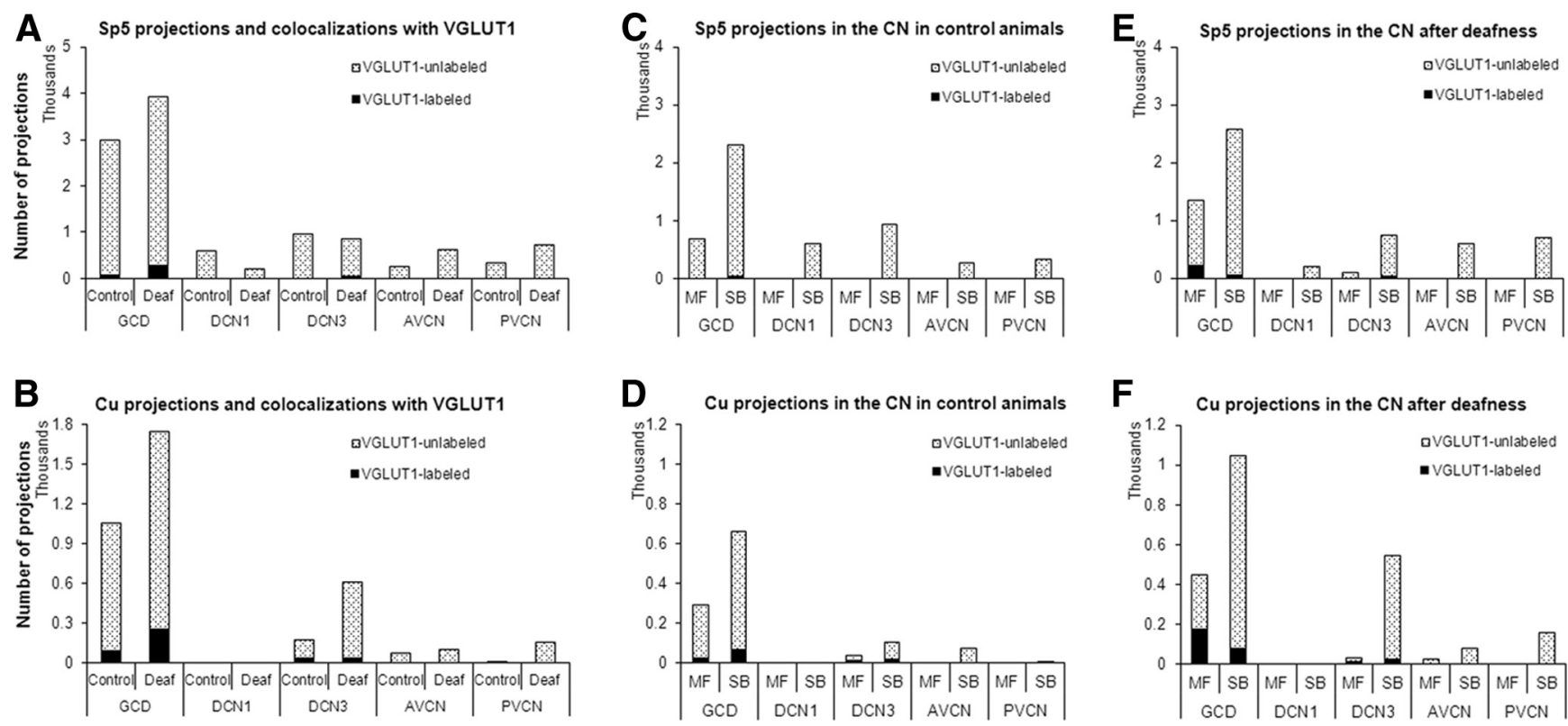

Figure 11. Counts of labeled $C u$ and Sp5 terminal endings colocalized with VGLUT1 in different subdivisions of the $\mathrm{CN}$ in control ( $\mathrm{Cu}, N=2 ; \mathrm{Sp} 5, N=2)$ and deafened (Cu, N $=2 ; \mathrm{Sp5}, N=2)$ guinea pigs. $A, B$, Only a few $C u$ and $S p 5$ terminals colabeled with VGLUT1. These terminals were mostly located in the GCD in both control and deafened guinea pigs. $C, E$, Numbers of VGLUT1-labeled Sp5 MFs significantly increased in the GCD following three week unilateral deafening. $\boldsymbol{D}, \boldsymbol{F}$, Numbers of VGLUT1-labeled Cu MFs significantly increased in the GCD following three week unilateral deafening.

minor subset of the somatosensory inputs to the CN, VGLUT1labeled MFs from both $\mathrm{Cu}$ and Sp5 were increased in the GCD after deafness, indicating that somatosensory compensation three weeks after unilateral deafness not only involves VGLUT2, but also VGLUT1.

\section{Discussion}

VGLUT1 decreases likely reflect ANF degeneration in the $\mathrm{CN}$ after unilateral deafness

Since type I ANF terminals in the CN exclusively colabel with VGLUT1 (Zhou et al., 2007), the decrease in VGLUT1, together with decreases in spiral ganglion counts, likely indicate decreased ANF inputs to CN neurons after unilateral deafening. Decreases in the synaptic vesicle marker, SV2 (D'Sa et al., 2007) and synaptophysin, also indicative of synaptic degeneration of ANFs in the CN following cochlear damage (Muly et al., 2002; D'Sa et al., 2007; Du et al., 2012), support this contention. The early decrease in VGLUT1 in the DCN1 after deafening (Zeng et al., 2009) is not maintained three and six weeks after deafening, suggesting a temporary shift of parallel fiber intrinsic connections (Zhou et al., 2007). The lack of change in VGLUT1 in the GCD and DCN3 for 
up to six weeks after deafening is consistent with previous studies (Benson et al., 1997), although downregulated synaptophysin was shown in a limited region of the DCN (Du et al., 2012). This may reflect input from a smaller number of ANF synaptic endings in the DCN (Cohen et al., 1972), which receives inputs from multiple sources, including descending, intrinsic, somatosensory pathways, as well as VCN T-stellate cells (Kane and Conlee, 1979; Weinberg and Rustioni, 1987; Benson et al., 1997; Ryugo et al., 2003; Haenggeli et al., 2005; Zhou et al., 2010; Ito et al., 2011; Zeng et al., 2011; Barker et al., 2012). Thus, cochlear damage can lead to synaptic plasticity in the DCN (Illing et al., 2005; McBain, 2008; Zeng et al., 2009; Hildebrandt et al., 2011; Kraus et al., 2011; Du et al., 2012), but may not result in significant downregulation of VGLUT1 in the DCN.

\section{Somatosensory nuclei are sources of the increased VGLUT2 in the $\mathrm{CN}$ after unilateral deafness}

The major objective of this study was to determine the source/s of the increased VGLUT2 in the CN following unilateral deafness. Several possibilities exist, including intrinsic pathways or synaptogenesis, or extrinsic inputs. Here, we focused on the two major sources of the VGLUT2-mediated inputs to the CN, the somatosensory brainstem nuclei, Sp5 and Cu (Zhou et al., 2007; Zeng et al., 2011). After volume- and location-matched tracer injections in $\mathrm{Cu}$ or Sp5 in three-week-deafened animals, there were significantly more terminal endings in the deafened animals. This increase occurred despite slightly larger injections in the normal animals. There was also little variation in the amount of $\mathrm{CN}$ labeling between control and deafened animals. The increased VGLUT2 levels, along with increased numbers of VGLUT2-labeled Sp5 and Cu terminals, likely indicate an increase in the number of axonal inputs from these somatosensory nuclei in response to auditory deafferentation. This VGLUT2mediated compensation begins at two weeks (Zeng et al., 2009) and is maintained up to six weeks (the longest time tested) following unilateral deafness. Other sources such as the vestibular (Barker et al., 2012), lateral reticular (Zhan and Ryugo, 2007; Cui and Shore, 2008), and contralateral cochlear nuclei (Doucet et al., 2009; Zhou et al., 2010) constitute other sources that may contribute to the increase of VGLUT2.

In addition to their upregulation in the GCD, more terminal endings from $\mathrm{Sp} 5$ and $\mathrm{Cu}$ were found in the ipsilateral magnocellular VCN three and six weeks after unilateral deafness. This redistribution of VGLUT2-labeled nonauditory inputs to regions previously dominated by VGLUT1-labeled ANF inputs has significant implications for signal-processing in the $\mathrm{CNs}$ of deafened animals. While physiological studies have suggested that increases in glutamatergic inputs to the DCN may explain deafness-induced hyperactivity and tinnitus (Dehmel et al., 2012), redistribution of these glutamatergic inputs to the VCN opens the way for contributions of the VCN to hyperactivity and tinnitus (Vogler et al., 2011).

\section{Sp5 and Cu MFs play an important role in the compensation of somatosensory input after hearing loss}

The granule cell-rich GCD is the main destination of somatosensory terminal endings (Weedman et al., 1996; Zhou and Shore, 2004; Zeng et al., 2011). MFs, which contain numerous round synaptic vesicles (Mugnaini et al., 1980), play an important role in activating DCN cells via granule cell axons (Weedman et al., 1996; Wright and Ryugo, 1996; Ryugo et al., 2003; Zeng et al., 2009, 2011). In normal hearing animals, MF terminals from Sp5 and $\mathrm{Cu}$ predominantly colabel with VGLUT2 (Zeng et al., 2011). Here, VGLUT2-labeled Sp5 and Cu MFs in the GCD were significantly increased, indicating that VGLUT2-MF-mediated so- matosensory input is amplified following three week unilateral deafness. The high density of $\mathrm{Na}^{+}$-channels and fast-gated presynaptic $\mathrm{Ca}^{+}$channels in MFs can produce a large but brief presynaptic $\mathrm{Ca}^{+}$influx, triggering transmitter release with high temporal precision (McBain, 2008). Thus, somatosensory MFs may provide a faster-acting pathway after hearing damage. This would be especially evident in the Sp5 to CN pathway since MFs from $\mathrm{Sp} 5$ showed a greater increase in the GCD compared with $\mathrm{MFs}$ from $\mathrm{Cu}$. These findings provide an anatomical basis for the decreased latencies of Sp5 activation of DCN principal cells after deafness (Shore et al., 2008). One undesirable consequence of the post-trauma neuroplasticity could be increased spontaneous rates in the $\mathrm{CN}$ neurons that have been observed after hearing loss (Brozoski et al., 2002; Sumner et al., 2005; Shore et al., 2008; Dehmel et al., 2012). This elevated neural activity in the DCN has been proposed as a physiological correlate of tinnitus (Brozoski and Bauer, 2005; Bauer et al., 2007; Kaltenbach, 2007, 2011). Tinnitus indeed may reflect a predominant increase in somatosensory synaptic strength to the CN (Dehmel et al., 2012). The present data provides a rationale for tinnitus treatment involving blocking the VGLUT2-mediated somatosensory input.

\section{Sp5 and Cu SBs are differentially increased across topographic maps of the $\mathrm{CN}$ after three week unilateral deafness}

Somatosensory SBs, located in DCN and the VCN shell region (Zhou and Shore, 2004; Zeng et al., 2011), likely mediate slowacting pathways. Here, auditory deafferentation resulted in more SB terminals from both SP5 and Cu to the CN, but with a different distribution. Like MFs, most SBs from Sp5 and Cu were located in the GCD in normal animals. But after three weeks of unilateral deafness, there were more VGLUT2-labeled Sp5 SBs in the VCN and more VGLUT2-labeled Cu SBs in DCN3. This was not seen one and two weeks after deafening (Zeng et al., 2009), suggesting that SBs and MFs are involved in longer term effects, but terminate in different regions of the $\mathrm{CN}$. The increased somatosensory SBs in VCN likely activate the principal neurons in the $\mathrm{VCN}$, increasing their role in auditory-somatosensory integration after deafness. The existence of a bushy-cell network in the VCN, for example, may facilitate these interactions since the dendritic inputs on bushy cells are of cochlear as well as noncochlear origin (Gómez-Nieto and Rubio, 2009).

Synaptic plasticity after cochlear damage is reflected in increased growth associated protein 43 (GAP43) in ipsilateral VCN. Deafness-induced GAP-43-mediated synaptic plasticity in the VCN is predominantly based on cholinergic afferents (Meidinger et al., 2006) and has been proposed to possibly reduce central hyperactivity and tinnitus (Kraus et al., 2011). The increased VGLUT2-labeled Sp5 terminals in the VCN shown in this study indicate that synaptic plasticity in the $\mathrm{VCN}$ is also mediated by glutamatergic inputs, which may increase the excitatory drive to the $\mathrm{CN}$ and produce tinnitus. It is possible that the cholinergic and glutamatergic amplifications after deafness counteract each other or work synergistically, concepts that require further investigation.

\section{References}

Abercrombie M (1946) Estimation of nuclear population from microtome sections. Anat Rec 94:239-247. CrossRef Medline

Barker M, Solinski HJ, Hashimoto H, Tagoe T, Pilati N, Hamann M (2012) Acoustic overexposure increases the expression of VGLUT-2 mediated projections from the lateral vestibular nucleus to the dorsal cochlear nucleus. PLoS One 7:e35955. CrossRef Medline

Bauer CA, Brozoski TJ, Myers K (2007) Primary afferent dendrite degener- 
ation as a cause of tinnitus. J Neurosci Res 85:1489-1498. CrossRef Medline

Benson CG, Gross JS, Suneja SK, Potashner SJ (1997) Synaptophysin immunoreactivity in the cochlear nucleus after unilateral cochlear or ossicular removal. Synapse 25:243-257. CrossRef Medline

Brozoski TJ, Bauer CA (2005) The effect of dorsal cochlear nucleus ablation on tinnitus in rats. Hear Res 206:227-236. CrossRef Medline

Brozoski TJ, Bauer CA, Caspary DM (2002) Elevated fusiform cell activity in the dorsal cochlear nucleus of chinchillas with psychophysical evidence of tinnitus. J Neurosci 22:2383-2390. Medline

Bukowska D (2002) Morphological evidence for secondary vestibular afferent connections to the dorsal cochlear nucleus in the rabbit. Cells Tissues Organs 170:61-68. CrossRef Medline

Burian M, Gstoettner W (1988) Projection of primary vestibular afferent fibres to the cochlear nucleus in the guinea pig. Neurosci Lett 84:13-17. CrossRef Medline

Cohen ES, Brawer JR, Morest DK (1972) Projections of the cochlea to the dorsal cochlear nucleus in the cat. Exp Neurol 35:470-479. CrossRef Medline

Cui YL, Shore S (2008) Topography of projections from the lateral reticular formation and the spinal trigeminal nucleus in the guinea pig cochlear nucleus. Assoc Res Otolaryngol Abstr 31:105-106.

Dehmel S, Pradhan S, Koehler S, Bledsoe S, Shore S (2012) Noise overexposure alters long-term somatosensory-auditory processing in the dorsal cochlear nucleus-possible basis for tinnitus-related hyperactivity? J Neurosci 32:1660-1671. CrossRef Medline

Doucet JR, Lenihan NM, May BJ (2009) Commissural neurons in the rat ventral cochlear nucleus. J Assoc Res Otolaryngol 10:269-280. CrossRef Medline

D'Sa C, Gross J, Francone VP, Morest DK (2007) Plasticity of synaptic endings in the cochlear nucleus following noise-induced hearing loss is facilitated in the adult FGF2 overexpressor mouse. Eur J Neurosci 26:666-680. CrossRef Medline

Du X, Chen K, Choi CH, Li W, Cheng W, Stewart C, Hu N, Floyd RA, Kopke RD (2012) Selective degeneration of synapses in the dorsal cochlear nucleus of chinchilla following acoustic trauma and effects of antioxidant treatment. Hear Res 283:1-13. CrossRef Medline

Glueckert R, Bitsche M, Miller JM, Zhu Y, Prieskorn DM, Altschuler RA, Schrott-Fischer A (2008) Deafferentation-associated changes in afferent and efferent processes in the guinea pig cochlea and afferent regeneration with chronic intrascalar brain-derived neurotrophic factor and acidic fibroblast growth factor. J Comp Neurol 507:1602-1621. CrossRef Medline

Gómez-Nieto R, Rubio ME (2009) A bushy cell network in the rat ventral cochlear nucleus. J Comp Neurol 516:241-263. CrossRef Medline

Hackett TA, de la Mothe LA (2009) Regional and laminar distribution of the vesicular glutamate transporter, VGluT2, in the macaque monkey auditory cortex. J Chem Neuroanat 38:106-116. CrossRef Medline

Hackett TA, Takahata T, Balaram P (2011) VGLUT1 and VGLUT2 mRNA expression in the primate auditory pathway. Hearing Res 274:129-141.

Hackney CM, Osen KK, Kolston J (1990) Anatomy of the cochlear nuclear complex of guinea pig. Anat Embryol 182:123-149. Medline

Haenggeli CA, Pongstaporn T, Doucet JR, Ryugo DK (2005) Projections from the spinal trigeminal nucleus to the cochlear nucleus in the rat. J Comp Neurol 484:191-205. CrossRef Medline

Hildebrandt H, Hoffmann NA, Illing RB (2011) Synaptic reorganization in the adult rat's ventral cochlear nucleus following its total sensory deafferentation. PLoS One 6:e23686. CrossRef Medline

Hioki H, Fujiyama F, Taki K, Tomioka R, Furuta T, Tamamaki N, Kaneko T (2003) Differential distribution of vesicular glutamate transporters in the rat cerebellar cortex. Neuroscience 117:1-6. CrossRef Medline

Illing RB, Kraus KS, Meidinger MA (2005) Reconnecting neuronal networks in the auditory brainstem following unilateral deafening. Hear Res 206:185-199. CrossRef Medline

Ito T, Bishop DC, Oliver DL (2011) Expression of glutamate and inhibitory amino acid vesicular transporters in the rodent auditory brainstem. J Comp Neurol 519:316-340. CrossRef Medline

Kaltenbach JA (2007) The dorsal cochlear nucleus as a contributor to tinnitus: mechanisms underlying the induction of hyperactivity. Prog Brain Res 166:89-106. CrossRef Medline

Kaltenbach JA (2011) Tinnitus: models and mechanisms. Hear Res 276:52-60. Medline

Kane ES, Conlee JW (1979) Descending inputs to the caudal cochlear nu- cleus of the cat: degeneration and autoradiographic studies. J Comp Neurol 187:759-783. CrossRef Medline

Kaneko T, Fujiyama F, Hioki H (2002) Immunohistochemical localization of candidates for vesicular glutamate transporters in the rat brain. J Comp Neurol 444:39-62. CrossRef Medline

Kraus KS, Ding D, Jiang H, Lobarinas E, Sun W, Salvi RJ (2011) Relationship between noise-induced hearing-loss, persistent tinnitus and growthassociated protein-43 expression in the rat cochlear nucleus: does synaptic plasticity in ventral cochlear nucleus suppress tinnitus? Neuroscience 194:309-325. CrossRef Medline

McBain CJ (2008) Differential mechanisms of transmission and plasticity at mossy fiber synapses. Prog Brain Res 169:225-240. CrossRef Medline

Meidinger MA, Hildebrandt-Schoenfeld H, Illing RB (2006) Cochlear damage induces GAP-43 expression in cholinergic synapses of the cochlear nucleus in the adult rat: a light and electron microscopic study. Eur J Neurosci 23:3187-3199. CrossRef Medline

Miller JM, Chi DH, O’Keeffe LJ, Kruszka P, Raphael Y, Altschuler RA (1997) Neurotrophins can enhance spiral ganglion cell survival after inner hair cell loss. Int J Dev Neurosci 15:631-643. CrossRef Medline

Miller JM, Le Prell CG, Prieskorn DM, Wys NL, Altschuler RA (2007) Delayed neurotrophin treatment following deafness rescues spiral ganglion cells from death and promotes regrowth of auditory nerve peripheral processes: effects of brain-derived neurotrophic factor and fibroblast growth factor. J Neurosci Res 85:1959-1969. CrossRef Medline

Moore DR, Kowalchuk NE (1988) Auditory brainstem of the ferret: effects of unilateral cochlear lesions on cochlear nucleus volume and projections to the inferior colliculus. J Comp Neurol 272:503-515. CrossRef Medline

Mugnaini E, Osen KK, Dahl AL, Friedrich VL Jr, Korte G (1980) Fine structure of granule cells and related interneurons (termed Golgi cells) in the cochlear nuclear complex of cat, rat and mouse. J Neurocytol 9:537-570. CrossRef Medline

Muly SM, Gross JS, Morest DK, Potashner SJ (2002) Synaptophysin in the cochlear nucleus following acoustic trauma. Exp Neurol 177:202-221. CrossRef Medline

Ryugo DK, Haenggeli CA, Doucet JR (2003) Multimodal inputs to the granule cell domain of the cochlear nucleus. Exp Brain Res 153:477-485. CrossRef Medline

Shore SE (2005) Multisensory integration in the dorsal cochlear nucleus: unit responses to acoustic and trigeminal ganglion stimulation. Eur J Neurosci 21:3334-3348. CrossRef Medline

Shore SE, Koehler S, Oldakowski M, Hughes LF, Syed S (2008) Dorsal cochlear nucleus responses to somatosensory stimulation are enhanced after noise-induced hearing loss. Eur J Neurosci 27:155-168. Medline

Sumner CJ, Tucci DL, Shore SE (2005) Responses of ventral cochlear nucleus neurons to contralateral sound after conductive hearing loss. J Neurophysiol 94:4234-4243. CrossRef Medline

Takamori S, Rhee JS, Rosenmund C, Jahn R (2001) Identification of differentiation-associated brain-specific phosphate transporter as a second vesicular glutamate transporter (VGLUT2). J Neurosci 21:RC182. Medline

Vogler DP, Robertson D, Mulders WH (2011) Hyperactivity in the ventral cochlear nucleus after cochlear trauma. J Neurosci 31:6639-6645. CrossRef Medline

Weedman DL, Pongstaporn T, Ryugo DK (1996) Ultrastructural study of the granule cell domain of the cochlear nucleus in rats: mossy fiber endings and their targets. J Comp Neurol 369:345-360. CrossRef Medline

Weinberg RJ, Rustioni A (1987) A cuneocochlear pathway in the rat. Neuroscience 20:209-219. CrossRef Medline

Wright DD, Ryugo DK (1996) Mossy fiber projections from the cuneate nucleus to the cochlear nucleus in the rat. J Comp Neurol 365:159-172. CrossRef Medline

Zappia JJ, Altschuler RA (1989) Evaluation of the effect of ototopical neomycin on spiral ganglion cell density in the guinea pig. Hear Res 40:29-37. CrossRef Medline

Zeng C, Nannapaneni N, Zhou J, Hughes LF, Shore S (2009) Cochlear damage changes the distribution of vesicular glutamate transporters associated with auditory and nonauditory inputs to the cochlear nucleus. J Neurosci 29:4210-4217. CrossRef Medline

Zeng C, Shroff H, Shore SE (2011) Cuneate and spinal trigeminal nucleus projections to the cochlear nucleus are differentially associated with vesicular glutamate transporter-2. Neuroscience 176:142-151. CrossRef Medline 
Zhan X, Ryugo DK (2007) Projections of the lateral reticular nucleus to the cochlear nucleus in rats. J Comp Neurol 504:583-598. CrossRef Medline

Zhou J, Shore S (2004) Projections from the trigeminal nuclear complex to the cochlear nuclei: a retrograde and anterograde tracing study in the guinea pig. J Neurosci Res 78:901-907. CrossRef Medline

Zhou J, Nannapaneni N, Shore S (2007) Vessicular glutamate transporters 1 and 2 are differentially associated with auditory nerve and spinal trigeminal inputs to the cochlear nucleus. J Comp Neurol 500:777-787. CrossRef Medline

Zhou J, Zeng C, Cui Y, Shore S (2010) Vesicular glutamate transporter 2 is associated with the cochlear nucleus commissural pathway. J Assoc Res Otolaryngol 11:675-687. CrossRef Medline 